Revue bibliographique pour le domaine irano-aryen

Volume 37-38-39 | 2018

Comptes rendus des publications de 2014-2016

\title{
Farhad Daftary, Gurdofarid Miskinzoda (eds.). The Study of Shi'i Islam. History, Theology and Law
}

\section{Mathieu Terrier}

\section{Q OpenEdition \\ 1 Journals}

\section{Édition électronique}

URL : http://journals.openedition.org/abstractairanica/42496

DOI : 10.4000/abstractairanica.42496

ISBN : 1961-960X

ISSN : 1961-960X

Éditeur :

CNRS (UMR 7528 Mondes iraniens et indiens), Éditions de l'IFRI

Référence électronique

Mathieu Terrier, « Farhad Daftary, Gurdofarid Miskinzoda (eds.). The Study of Shi'i Islam. History,

Theology and Law », Abstracta Iranica [En ligne], Volume 37-38-39 | 2018, document 1, mis en ligne le 10 mars 2018, consulté le 27 septembre 2020. URL : http://journals.openedition.org/abstractairanica/ 42496 ; DOI : https://doi.org/10.4000/abstractairanica.42496

Ce document a été généré automatiquement le 27 septembre 2020.

Tous droits réservés 


\title{
Farhad Daftary, Gurdofarid Miskinzoda (eds.). The Study of Shi'i Islam. History, Theology and Law
}

\author{
Mathieu Terrier
}

\section{RÉFÉRENCE}

Farhad Daftary and Gurdofarid Miskinzoda (eds.), The Study of Shi'i Islam. History, Theology and Law, I.B.Tauris Publishers, London - New York, The Institute of Ismaili Studies, London, 2014, 616 p., ISBN: 9781780765068

1 Cet ouvrage présente à la fois un bilan critique des études consacrées au shi'isme depuis un demi-siècle et un état des lieux des recherches en cours. Ses huit chapitres, comptant autant d'introductions substantielles, embrassent les domaines fondamentaux de la pensée shi'ite : l'historiographie (I), l'exégèse (II), le hadìth (III), le droit (IV), l'autorité (V), la théologie (VI), les rites (VII), la philosophie (VIII). Si l'ouvrage traite équitablement de l'imâmisme, de l'ismaélisme et du zaydisme, on regrettera l'absence d'études sur le nușayrisme-'alawisme.

a section I, l'introduction de W. Madelung fait d'abord droit aux nouvelles hypothèses sur les débuts de l'islam suscitées par l'étude des sources shi'ites. F. Daftary, "The Study of the Ismailis: Phases and Issues", revient sur l'évolution des études ismaéliennes, de la construction à la déconstruction de la «légende noire » dont cette religion fit l'objet. M.A. Amir-Moezzi, dans "Reflections on the Expression din 'Alì : the Origins of the Shi'i Faith", enquête sur l'apparition et les usages d'une expression ancienne semblant désigner le shi'isme comme une religion distincte de celle de Muhammad. N. Rabbat, dans "Al-Maqrizī's Connection to the Fatimids", analyse la présentation favorable du contre-califat fatimide par un historien sunnite tardif. Shi'i Tafsir ?" et distingue trois phases successives : la période de formation dominée 
par l'autorité des imâms, la période classique marquée par l'émergence des 'ulamā', et la période moderne caractérisée par un retour aux traditions orales. M. A. AmirMoezzi, dans "The Tafsìr of al-Hibarī (d. 286/899) : Qur'anic Exegesis and Early Shi'i Esotericism" présente un ouvrage caractéristique du "commentaire personnalisé » shi'ite où affleure la thèse de la falsification du Coran. D. Hollenberg, "The Empire Writes Back: Fatimid Ismaili Ta'wîl (Allegoresis) and the Mysteries of the Ancient Greeks", traite du Tafsir produit par les missionnaires ismaéliens de l'Empire fatimide. Enfin, M. M. Bar-Asher, dans "The Authority to Interpret the Qur'an", démontre que la croyance en "l'Occultation majeure" du dernier imâm permit aux 'ulamä' de s'approprier la prérogative herméneutique de l'imâm.

4 Dans la section III, l'introduction d'E. Kohlberg rappelle le sens particulier du terme hadìth pour les shi'ites ainsi que les positions antagonistes des rationalistes uṣūlì et traditionalistes akhbārī. M. M. Dakake, dans "Writing and Resistance : The Transmission of Religious Knowledge in Early Shi'ism”, voit dans la mise à l'écrit précoce et systématique des traditions une spécificité du shi'isme originel due à sa situation minoritaire. R. Vilozny, dans "Pre-Būyid Literature: The Case of al-Barqī from Qumm (d. $274 / 888$ or 280/894) in Twelve Sections", se penche sur l'un des plus anciens recueils de hadiths shi'ites. G. Miskinzoda, dans "The Story of 'Pen and Paper' and its Interpretations in Muslim Literary and Historical Tradition", étudie un fameux récit relatif à la maladie du Prophète que les shi'ites interprètent comme une confirmation de leur foi.

5 La section IV sur le droit (figh) nous semble parcellaire et lacunaire. C. Melchert, dans "Renonciation (Zuhd) in the Early Shi'i Tradition", traite plutôt d'éthique que de droit en comparant les propos attribués aux imâms shi'ites et ceux des zuhhād, les "pieux ascètes » proto-sunnites. I. K. Poonawala, "The Evolution of al-Qāḍi al-Nu'mān's Theory", examine les origines du droit ismaélien codifié sous les Fatimides dans les Da'ā'im al-islām de Qādī al-Nu'mān (m. 363/974). S. Z. al-Wazir, dans "The Theory of Māl among the Zaydīs", analyse la fonction de la richesse (māl) chez les zaydites hadawites dans un article manquant singulièrement de distance critique. Aucune étude ne porte sur le shi'isme duodécimain.

6 La section $\mathrm{V}$, sur l'autorité, s'ouvre par une remarquable introduction d'A. Newman montrant que le paradigme des études sur l'autorité cléricale shi'ite reste figé depuis la Révolution iranienne de 1979. S. Rizvi, “'Seeking the Face of God': The Safawid Tradition's Conceptualisation of Walāya Takwiniyya", propose un historique de cette notion désignant l'autorité surnaturelle des imâms à partir de son élaboration par les philosophes de l'époque safavide. P. E. Walker, "The Role of the Imam-caliph as Depicted in Official Treatises and Documents Issued by the Fatimids", examine la manière dont les Fatimides concevaient la théorie et la pratique de l'imâmat. A. Newman, “'Minority Reports' : Twelver Shi'i Disputations and Authority in the Būyid Period", montre que les positions théologiques et juridiques des savants rationalistes de l'époque bouyide s'éloignaient des vues majoritaires de la communauté imâmite pour se rapprocher des positions sunnites.

7 La section VI est dominée par les travaux de W. Madelung. Son introduction retrace l'évolution des études sur la théologie shi'ite. Dans "Early Imāmī Theology as Reflected in the Kitāb al-Käfi of al-Kulayn̄”", il soutient la congruence des conceptions exprimées dans la première partie de cet ouvrage canonique avec la théologie rationaliste des mu'tazilites. H. Ansari et S. Schmidtke, dans "Al-Shaykh al-Ṭūsî: His Writings on 
Theology and their Reception", reviennent sur l'œuvre pléthorique d'un des plus influents savants imâmites de la période post-bouyide pour faire apparaître aussi ses liens possibles avec la dernière école mu'tazilite. Cette section ne dit rien de la théologie ésotérique et non rationnelle du shi'isme primitif.

Dans la section VII, l'introduction de G. H. Hawting insiste sur la complémentarité des approches historiques et anthropologiques. S. Mervin, '“Āshūrā' Rituals, Identity and Politics : A Comparative Approach (Lebanon and India)", s'intéresse à la réinvention continue des cérémonies de commémoration du martyre du troisième imâm chez les shi' ites d'Inde comme du Liban. H. Elnazarov, dans "The Luminous Lamp : the Practice of Chirāgh-i rawshan among the Ismailis of Central Asia", propose une analyse détaillée d'une cérémonie propre aux ismaéliens nizarites d'Asie centrale.

Vection VIII ne contient que deux articles, ce qui ne reflète pas l'importance de la philosophie en milieu shi'ite. L'introduction de D. De Smet fait un point très éclairant sur la notion même de philosophie shi'ite, les acquis de la recherche et les points d'interrogation subsistants. T. Mayer, "Shahrastānī's Ḥanîf Revelation: A Shi'i Philosophico-Hermeneutical System », montre comment ce théologien et hérésiographe ismaélien renversa certaines perspectives avicenniennes. N. al-Bizri, dans "Philosophising at the Margins of 'Shi'i Studies': Reflections on Ibn Sinnā's Ontology”, s'en tient à quelques réflexions générales sur «l'héritage métaphysique œcuménique d'Avicenne » sans aborder aucune spécificité de la philosophie shi'ite.

En somme, malgré le caractère nécessairement inégal des contributions et, par suite, le traitement lacunaire ou trop rapide de certains thèmes importants, voici un ouvrage qui devrait faire date dans l'histoire des études shi' ites.

\section{AUTEURS}

\section{MATHIEU TERRIER}

CNRS, Laboratoire d'études sur les monothéismes 